\title{
Correspondence
}

The Editor,

Journal of Glaciology

SIR,

\section{Detection of hills from radar data in central-northern Greenland}

In 1993, NASA initiated an airborne remote-sensing program in conjunction with coordinated surface measurements to determine the mass balance of the Greenland ice sheet. Starting in 1995, NASA combined various efforts on mass-balance studies into one coordinated effort called Program in Arctic Regional Climate Assessment (PARCA). We have been participating by performing airborne ice-thickness measurements using a coherent radar depth sounder (Chuah, 1996). The radar operates at $150 \mathrm{MHz}$, and is capable of measuring polar ice-sheet thickness to about $4000 \mathrm{~m}$ in colder ice and to lesser thickness in temperate glaciers. The aircraft normally flies at an altitude of $500 \mathrm{~m}$ with an airspeed of about $130 \mathrm{~m} \mathrm{~s}^{-1}$ during the Greenland mission, and is equipped with a navigation system controlled by the Global Positioning System (GPS) and a laser altimeter for measuring surface topography (Krabill and others, 1995).

We noticed two internal ice features having strong radar echoes, while examining radar data collected during sorties flown in 1995 (Chuah and others, 1996) and 1996 (Legarsky and others, 1997) over the central-northern Greenland ice sheet. To the best of our knowledge, these ice features have not been reported. In 1997, we investigated further by planning crossing flight-lines over the features. The 1995 and
1996 features are located at the coordinates $\left(78^{\circ} 18^{\prime} \mathrm{N}\right.$, $\left.49^{\circ} 53^{\prime} \mathrm{W}\right)$ and $\left(79^{\circ} 22^{\prime} \mathrm{N}, 52^{\circ} 13^{\prime} \mathrm{W}\right)$, respectively. Figure la shows the location of the two features in Greenland. The map in Figure lb shows the trajectories of the two 1997 missions flown out of Thule Air Base, and the location of the two features as well as several other features found in 1997.

Figure 2 shows a comparison of 1995 and 1997 passes from nearly identical trajectories over a feature; clearly, measurement of the feature is repeatable. Examination of the ice-layer undulation over the feature leads us to believe the feature may be a hill. The radar intensity at the highest point on the feature matches the radar intensity of bottom bedrock at a depth corresponding to the feature's highest point. This suggests the feature is in the main antenna beam and not a side lobe, since the first side lobe is $26 \mathrm{~dB}$ down from the main beam. The 1997 image of the approximately orthogonal flight over the feature is shown in Figure 3a. Again, a feature is imaged; however, there appear to be two peaks in the orthogonal direction. Internal ice-layer undulations are also imaged over the two-peaked feature's orthogonal view. Using the crossing flight-lines over the feature, we estimate the height of the hill peak to be approximately $656-672 \mathrm{~m}$, based on the cross-track $3 \mathrm{~dB}$ beamwidth of the antenna. The hill extent in the approximate east-west direction is at least $9 \mathrm{~km}$, and in the approximate north-south direction at least $12 \mathrm{~km}$.

An approximate $45^{\circ}$ crossing flight over the second feature is shown in Figure 3b. Figure 4 shows a comparison of

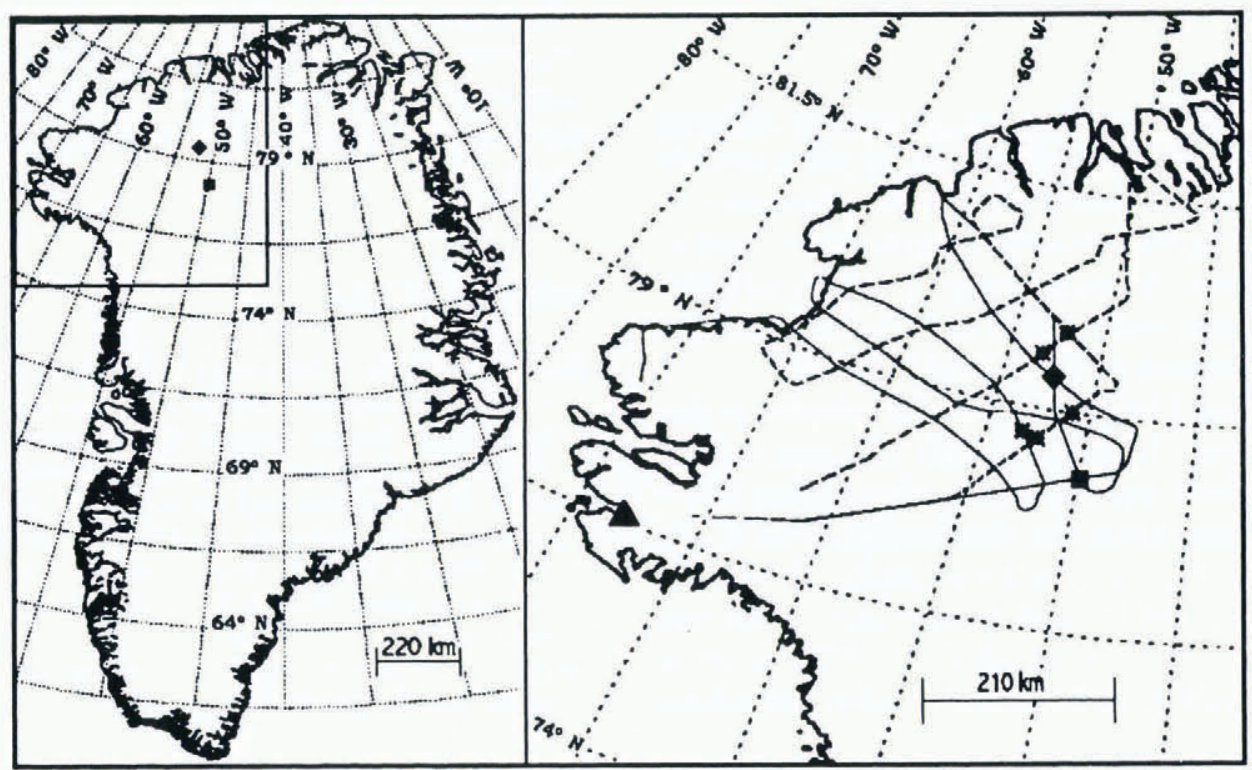

(a)

(b)

Fig. 1. (a) Map of north-central Greenland showing the location of two hills. Radar echograms of the hill shown by a diamond are presented in Figures 2 and $3 a$. Radar echograms of the hill illustrated by a square are presented in Figures $3 b$ and $4 .(b)$ Expanded view of the map of north-central Greenland (rectangle in (a) outlines the zooming area). The two 1997 flight-lines are shown here as dashed (27 May) and solid (28 May) lines. As in (a), the locations of the two hills are shown as a diamond and a square on the map, respectively. The other possible hills are shown as asterisks on the map. Thule Air Base is indicated by a triangle. 

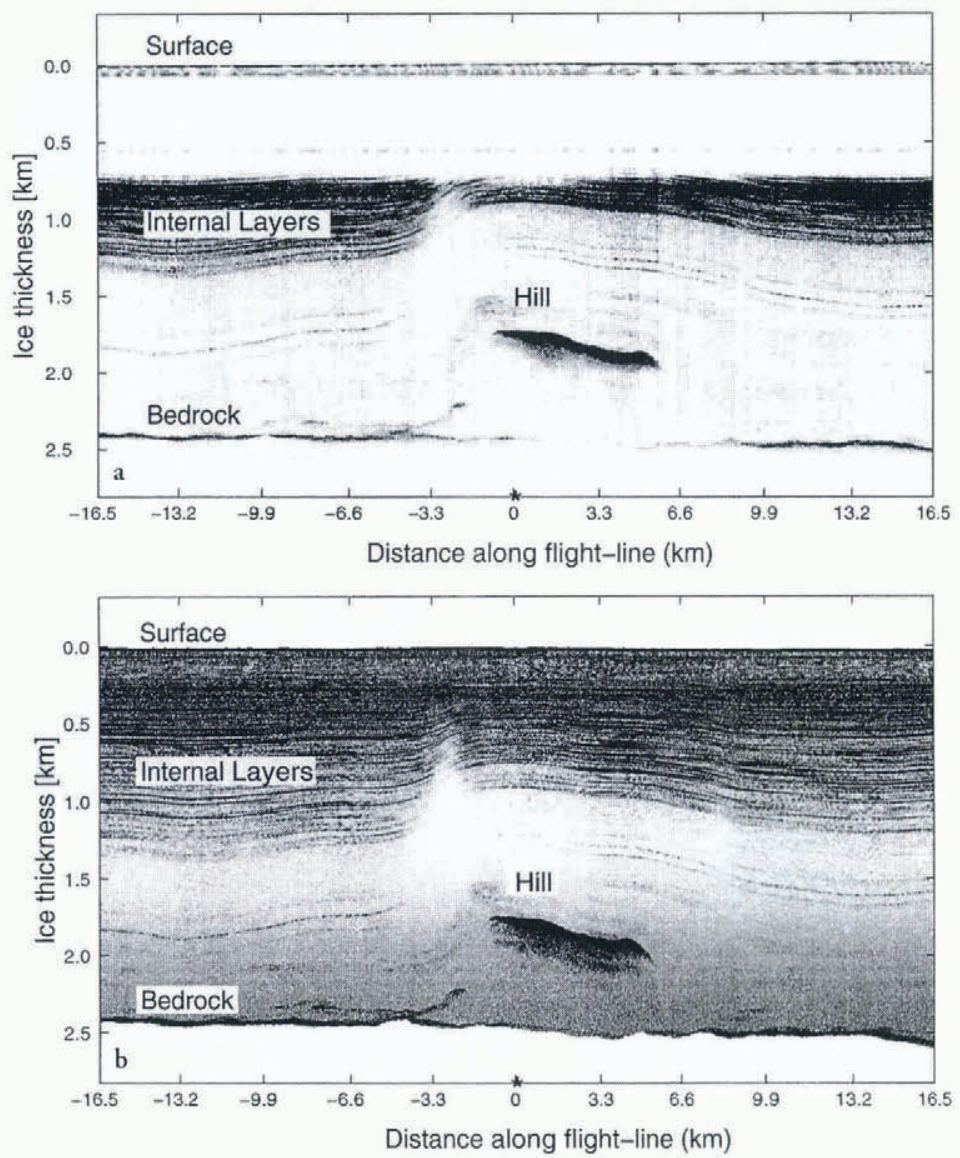

Fig. 2. (a) Radar echogram of ice thickness recorded from a 1995 flight showing a hill under the ice. Internal layers in about the first $700 \mathrm{~m}$ of ice are not seen, due to excessive receiver blanking. An asterisk indicates the coordinates of the crossing flight-line in 1997. (b) Radar echogram of ice thickness recorded from a 1997 flight (approximately the same flight-line as in (a)) showing a hill under the ice. An asterisk indicates the coordinates of the crossing flight-line in 1997.
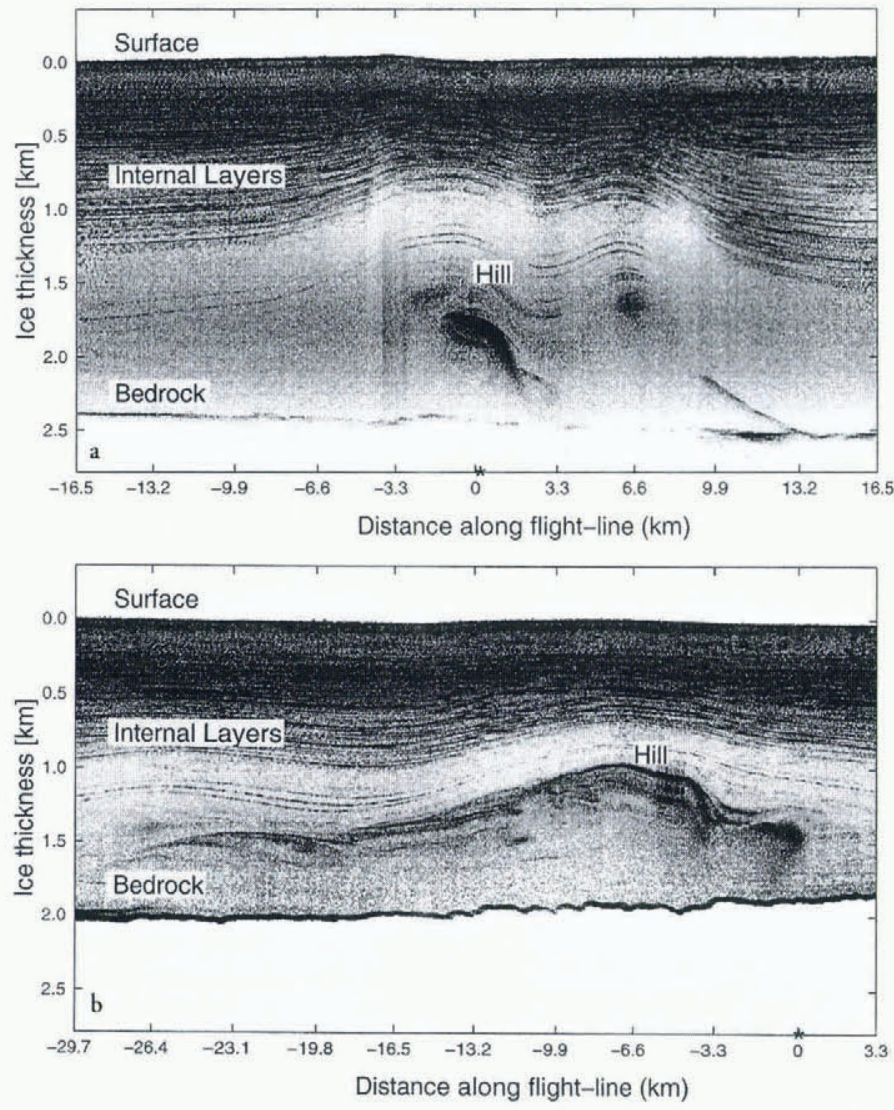

Fig. 3. (a) Radar echogram of ice thickness from a 1997 flight-line that crosses the lines flown in 1995 and 1997 over a hill. An asterisk indicates the coordinates of the crossing flight-line. (b) Radar echogram of ice thickness from a 1997 flight-line that crosses the lines flown in 1996 and 1997 over another hill. An asterisk indicates the coordinates of the crossing flight-line. 

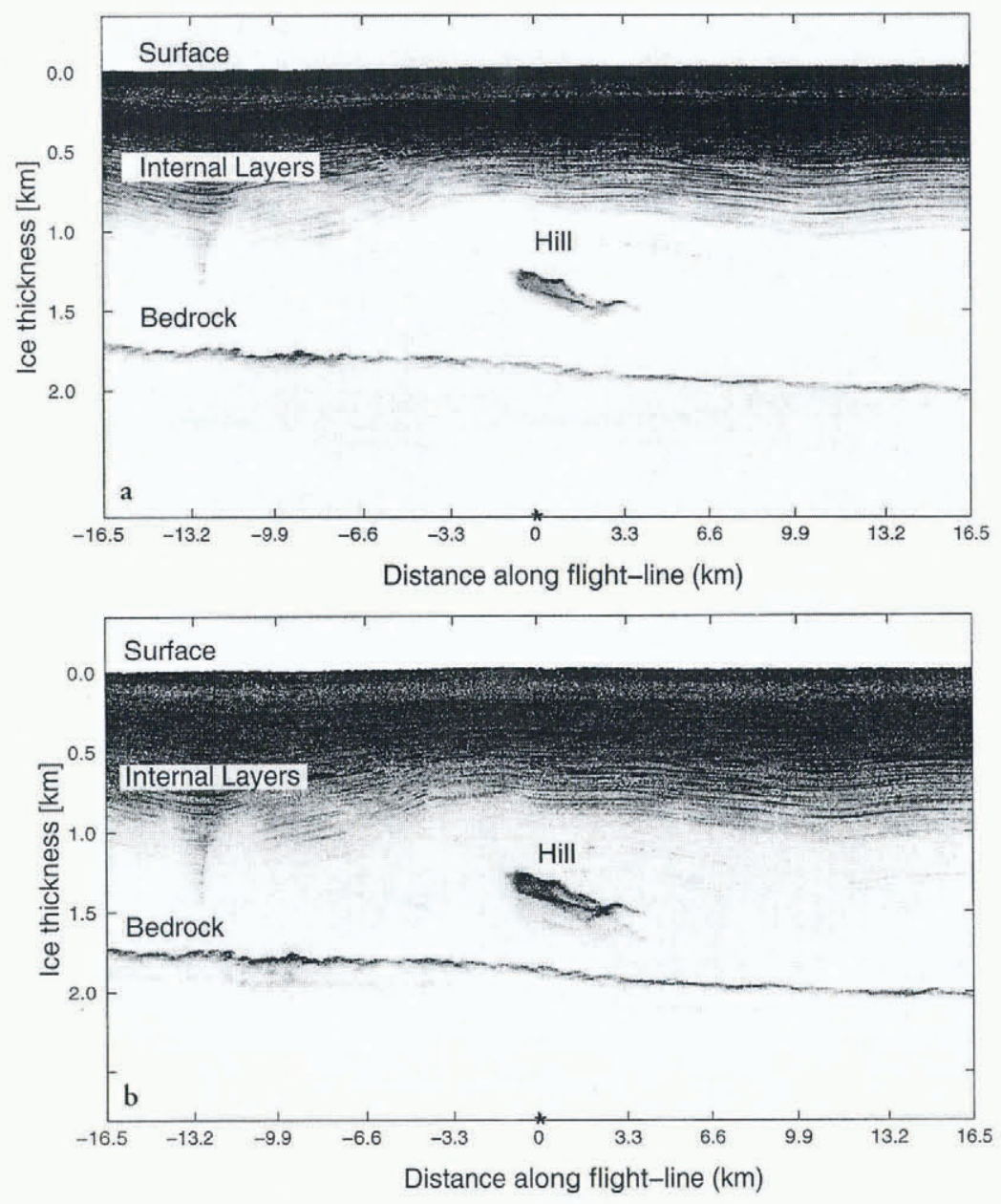

Fig. 4. (a) Radar echogram of ice thickness recorded from a 1996 flight showing a hill under the ice. An asterisk indicates the coordinates of the crossing flight-line in 1997. (b) Radar echogram of ice thickness recorded from a 1997 flight (approximately the same flight-line as in (a)) showing a hill under the ice. An asterisk indicates the coordinates of the crossing flight-line in 1997.

1996 and 1997 passes from nearly identical trajectories over a feature; again, measurement of the feature is repeatable. Presence of internal ice undulations on each pass over the feature indicates this feature may also be a hill. We examined the radar intensity at the highest peak of the feature and compared it to the radar intensity of bedrock at an equivalent depth. The radar intensities show strong agreement with one another. Using the same reasoning as for the first hill, we believe this hill to be located in the main antenna beam. The highest peak of the hill is estimated to be about $948-956 \mathrm{~m}$ using the cross-track $3 \mathrm{~dB}$ antenna beamwidth. We estimate the hill extent in the approximate north-south direction to be at least $4 \mathrm{~km}$, and in the southeast-northwest direction at least $26 \mathrm{~km}$.

In addition to the two hills discovered, we found other similar features in our radar data from around this area during the same 1997 Greenland mission. We examined the ice-layer undulations over each feature. We also compared echo intensity at the highest point on each feature with that from bottom bedrock at a depth corresponding to the feature's highest point, to verify that the echo was from the main antenna beam and not the side lobe. Based on these observations, we concluded that these echoes are from hills located at about $\left(78^{\circ} 40^{\prime} \mathrm{N}, 52^{\circ} 22^{\prime} \mathrm{W}\right),\left(78^{\circ} 43^{\prime} \mathrm{N}, 52^{\circ} 11^{\prime} \mathrm{W}\right)$, $\left(79^{\circ} 1^{\prime} \mathrm{N}, 50^{\circ} 54^{\prime} \mathrm{W}\right), \quad\left(79^{\circ} 38^{\prime} \mathrm{N}, 53^{\circ} 9^{\prime} \mathrm{W}\right)$ and $\left(79^{\circ} 55^{\prime} \mathrm{N}\right.$, $\left.52^{\circ} 7^{\prime} \mathrm{W}\right)$.

We strongly believe that these features are hills located off the flight track. These hills may be controlling ice flow and playing a key role in the ice dynamics in this region.
From the existing data we have not been able to identify the exact height and extent of these hills. A closely spaced grid pattern is essential to define these. We are making plans for a 1998 or 1999 mission to fly a detailed systematic grid over the area to map all these features and others that may exist in the area. We may be able to answer at least some of the questions after these missions.

Radar Systems and Remote Sensing Laboratory, Justin Legarsky The University of Kansas, 2291 Irving Hill Road, Lawrence, Kansas 66045, U.S.A. AnTHONY Wong Torry AKIns

\section{August 1997}

\section{REFERENCES}

Chuah, T. S. 1996. Design and development of a coherent radar depth sounder for measurement of Greenland ice sheet thickness. (D.E. thesis, University of Kansas.)

Chuah, T. S., S. P. Gogineni, C. Allen and B. Wohletz. 1996. Radar thickness measurements over the northern Greenland ice sheet. Lawrence, KS, University of Kansas. Radar Systems and Remote Sensing Laboratory. (Technical Report 10470-3.)

Krabill, W. B., R. H. Thomas, C. F. Martin, R. N. Swift and E. B. Frederick. 1995. Accuracy of airborne laser altimetry over the Greenland ice sheet. Int. F. Remote Sensing, 16 (7), 1211-1222.

Legarsky, J.J., S. P. Gogineni, C. Allen, T. S. Chuah and Y. C. Wong. 1997. Radar thickness measurements over the northern part of the Greenland ice sheet: 1996 results. Lawrence, KS, University of Kansas. Radar Systems and Remote Sensing Laboratory. (Technical Report 10470-6.) 